\title{
UMA PROFESSORA MUITO MALUQUINHA: ESCOLA, SACRALIDADE E PROFANAÇÃO
}

\section{INTRODUÇÃO}

A imagem estampada na capa do livro mostra uma mulher jovem com a língua de fora. Ela pisca um dos olhos e usa enrolado na ponta do cabelo um lápis. $\mathrm{Na}$ sua cabeça, um chapéu de duas pontas com a letra "N" bordada na frente. Por fim, vemos por dentro do largo casaco vermelho a mão direita próxima ao peito em um gesto patriótico. Essa mão carrega uma pasta em que podemos ler a palavra "Chamada" e abaixo dela a palavra "Turma", mas a palavra que vem abaixo está incompleta "Profes". O livro de que estamos falando é Uma professora muito maluquinha, publicado por Ziraldo em 1995 e já considerado um dos clássicos do autor e da nossa literatura infantil ao lado de $\mathbf{O}$ menino maluquinho, o que justifica a escolha dele como objeto de nosso estudo. Em várias de suas entrevistas, o autor mineiro diz ter tentando, na ilustração da capa de $\mathbf{O}$ menino maluquinho, associar a ideia de loucura com a de uma pessoa que se veste como Napoleão e reclama ser o imperador francês. A imagem é, obviamente, replicada na capa deste livro em que Ziraldo brinca com o estereótipo da professora.

Curioso é o fato de que não sentimos um estranhamento ao ver uma criança com as vestes napoleônicas, (neste caso trocando o chapéu por uma panela), ao passo que nos soa, no mínimo, curioso vermos uma professora vestida de maneira semelhante. As próprias palavras escritas na pasta que ela carrega consigo são dignas de uma breve análise. Enquanto "chamada" e "turma", vocábulos

\footnotetext{
${ }^{1}$ Graduado em Letras: Português/Inglês pela Universidade do Extremo Sul Catarinense - UNESC (2011). Mestrando do Programa de Pós-Graduação em Educação da UNESC. Bolsista do Programa de Suporte à Pós-Graduação de Instituições de Ensino Particulares (PROSUP/CAPES); debona12@hotmail.com

2 Graduado em Letras pela Universidade do Extremo Sul Catarinense - UNESC (1991). Mestre em Letras (Inglês e Literatura Correspondente) pela Universidade Federal de Santa Catarina - UFSC (1996) e doutor em Letras (Inglês e Literatura Correspondente) pela UFSC (2000). Professor da Universidade do Extremo Sul Catarinense no curso de Letras e no Programa de Pós-Graduação em Educação; glad@unesc.net
} 
que se referem a rituais que, dentro do contexto escolar, funcionam com sentido de controle e limitação do próprio espaço físico dos alunos, aparecem por inteiro, a palavra "Profes" está assim, incompleta. Estaria Ziraldo nos indicando que essa professora não é, na verdade, uma professora "completa"?

Essa incompletude e esse estranhamento causados pela imagem de uma professora maluquinha levam a uma indagação acerca da figura docente, ainda ligada à ideia de controle e de ações (a chamada, a tarefa de casa, o castigo, etc.) que zelam pela hegemonia de sua identidade dentro da escola e aos olhos dos pais e de seus colegas de profissão. Dentro dessa perspectiva, o discurso do professor soa "[...] como se só houvesse a sua verdade e como se o que diz fosse conclusivo, completo, não deixando espaço nem lugar para a dúvida, para o conflito, para a contradição, para a falta, que o habitam e constroem a sua subjetividade" (CORACINI, 2003, p.333). A própria escola ainda permanece sendo uma instituição dotada de tons sagrados na medida em que preserva a supremacia de seus rituais e de seus sacerdotes, os professores. Dentro desse contexto, a escolha pela obra de Ziraldo se justifica por se tratar de um clássico de nossa literatura infantil e também por trazer em sua capa uma ilustração que questiona o estereótipo de seriedade e controle ligado à identidade docente.

É importante salientar que trabalhamos aqui com o ponto de vista de que as identidades são construídas socialmente e possuem, portanto, um caráter sempre inacabado, exposto à constante construção e reconstrução. A identidade do professor é criada e recriada a partir dos discursos e dos modos pelos quais a figura do mestre é representada nesses discursos que circulam em determinada sociedade. Hall (2015, p.12) confirma isso ao dizer que "[...] à medida que os sistemas de significação e representação cultural se multiplicam, somos confrontados por uma multiplicidade desconcertante e cambiante de identidades possíveis [...]". Assim, é possível entender que uma sociedade constrói imagens do que é ser professor com base em uma série de características mais ou menos estáveis, mas nunca rígidas, uma vez que novos discursos e novas formas de representação do professor são produzidos continuamente.

Diante disso, com a ajuda de teóricos como Hall (2014), Bakhtin (2013), Larrosa (2015), Agambem (2007) e outros, este trabalho propõe uma reflexão acerca da possibilidade de rompimento da sacralidade do espaço escolar a partir da análise e discussão de três tópicos: a racionalidade, o controle do riso e os rituais 
sagrados do ambiente escolar. Dentre os diversos elementos constitutivos da narrativa de ficção, a pesquisa focará o papel da personagem principal a fim de atingir seu objetivo principal e responder qual concepção de educação está representada nesta obra de Ziraldo.

\section{A RACIONALIDADE AUTORITÁRIA}

No início da história, o narrador, um dos alunos da professora maluquinha, a descreve como um anjo que voa pela sala, com estrelas no lugar dos olhos, voz e jeito de sereia, vento soprando no cabelo o tempo todo, riso solto como passarinho, uma artista de cinema (para os meninos), fada madrinha (para as meninas), enfim, "Ela era uma professora inimaginável." (ZIRALDO, 1995, p.11). Chamo a atenção aqui para o fato de que o riso é posto em pé de igualdade com todas as outras características, digamos, fantasiosas. Podemos considerar isso como um indicativo de que para os alunos essa professora é diferente das demais, e que o fato de ela rir e por isso ser considerada louca era uma concretização das fantasias deles. Assim, a identidade da professora é construída, já nessas primeiras páginas, com base em uma característica que a contrapõe às demais docentes: 0 riso.

A sala de aula descrita pelo narrador é um ambiente divertido em que a professora utiliza jogos como par ou ímpar, forca, jogo da rima, caça-palavras; todos eles como recursos didáticos. Um detalhe importante é ressaltado pelo narrador ao mencionar que a professora em certas ocasiões dividia as equipes entre meninos e meninas para o jogo do par ou ímpar; quando isso acontecia: "Como havia dezessete meninos e dezesseis meninas, ela reforçava o time feminino. Mas, às vezes, o time dela perdia." (ZIRALDO, p.25, 1995). Nesse episódio é possível ver que a atitude da professora não é de distanciamento, buscando preservar seu papel de autoridade, ao contrário, ela se insere na brincadeira e corre, inclusive, o risco de perder, como mencionado no trecho acima.

Aqui, o medo de perder no jogo é semelhante ao medo que muitos docentes têm diante do fracasso ao lidar com perguntas para as quais não têm resposta. Tal situação é fruto de uma hipervalorização da racionalidade e do cientificismo, características que pesam sobre as instituições de ensino e, consequentemente, sobre os professores que nelas lecionam. A esse respeito, 
Subirats (1986, p.97) nos chama a atenção para o que chama de uma "razão destrutiva". De acordo com o autor

Nada nem ninguém atentou contra a razão; nada ameaça a sua existência. Ela não foi destruída: ela é destrutiva. [...] Ela se caracteriza por convergir com a práxis institucional das ciências e seu desenvolvimento indefinido, mas não se esgota apenas na dimensão agressiva e no caráter incontrolado desse desenvolvimento científico.

A razão, portanto, converte-se em uma espécie de religião para a qual todos devem pagar tributo. Para atender a essa racionalidade, a escola deve formar estudantes capazes de aceitar a superioridade de seus mestres e da verdade científica. Nesse contexto, o temor de admitir que se possa vacilar, não sabendo a resposta certa para a pergunta do aluno, apenas reitera uma identidade docente ligada à ideia de um sujeito dono da verdade, de senhor da sala de aula.

Em outro episódio, os alunos, ao verem um globo terrestre na secretaria da escola, questionam a professora:

'E como é que a gente não cai? A gente mora dentro?' Ela disse: 'Amanhã vamos fazer uma excursão ao ginásio para o professor de Geografia explicar para nós por que a gente não cai do globo terrestre'. (ZIRALDO, 1995, p.41)

Embora o texto não deixe claro se a professora sabe ou não a resposta exigida, ela, ao não responder ao questionamento dos estudantes, preferindo consultar um colega de outra área sobre o tema, demonstra não reivindicar para si o papel de detentora de todas as respostas. Outra característica importante é o fato de ela proporcionar uma abertura para questionamentos que não estejam prédeterminados pelo currículo escolar, ou seja, a pergunta foi feita pelos alunos não durante uma aula de Geografia e, mesmo assim, não foi ignorada, diferente do que pressupõe a cultura estritamente curricular em que o saber compartimentado exige que as perguntas sejam feitas na hora certa e apenas "sobre o assunto".

Agindo de forma a priorizar a curiosidade genuína dos seus alunos e de admitir não poder respondê-los de imediato, ela questiona a sua própria identidade ligada a uma racionalidade que reclama ser detentora da verdade científica e que reitera a "[...] concepção de sujeito centrado, cartesiano que, pelo uso efetivo da razão, permite que o objeto fale, que o objeto se apresente, se declare, enfim, se dê a conhecer, sem a interferência de paixões, de interesses, de desejos [...] 
(CORACINI, 2003, p. 319)". É essa a identidade docente que a escola busca preservar e que coincide com aquela demonstrada por Larrosa (2015) na seção anterior ao aproximar a figura do docente a de um pregador. Para o professor, confessar que não sabe a resposta é um pecado.

\section{O RISO CONTROLADO}

Ainda nas primeiras páginas, o narrador enfatiza o ambiente alegre da sala de aula com todos os jogos e brincadeiras promovidos pela professora maluquinha. Esse comportamento da turma, no entanto, perturba o silêncio que a escola tanto preza, o que se evidencia na ilustração que mostra a diretora da escola abrindo a porta da sala de aula: "E era tanto barulho na sala, e era tanto riso e tanta alegria que lá vinha a diretora saber o que estava acontecendo: 'Vocês estão prejudicando as outras classes'."(ZIRALDO, 1995, p.32). Na ilustração, fica nítido o contraste que o autor tenta estabelecer entre a imagem autoritária da diretora, retratada com cabelos presos, óculos de grau e um semblante zangado, e a figura alegre da professora maluquinha, com cabelos soltos e um sorriso no rosto. Quanto aos motivos da visita da diretora, o texto nos revela que eles são o riso e a alegria em demasia, fatores que estavam prejudicando as demais salas de aula que, segundo a diretora, necessitavam de silêncio.

Aqui, trazemos Larrosa (2015) novamente para enfatizar a ideia de que, no contexto educacional, o riso não aparece por acaso no mesmo rol de absurdos comparáveis a voar, como citado no início do livro. Ao estabelecer as relações entre o riso e a pedagogia, o autor espanhol argumenta:

Talvez meu objetivo principal em falar do riso seja a convicção de que o riso está proibido, ou pelo menos bastante ignorado, no campo pedagógico. E sempre pode ser interessante pensar um pouco por que um campo proíbe ou ignora. [...] Que acontece, então, na Pedagogia, para que se ria tão pouco? Eu tenho duas hipóteses. A primeira é que, na Pedagogia, moralizase demasiadamente. E o discurso moralizante tem um tom grave, sério, um certo tom patético. A segunda hipótese é que o campo pedagógico é um campo constituído sobre um incurável otimismo. E o riso está sempre associado a uma certa tristeza, a uma certa melancolia, a um certo desprendimento. (LARROSA, 2015, p.171)

Aplicando a fala do teórico ao nosso caso, veremos que a personagem da diretora da escola representa exatamente esse discurso moralizante, sério, 
dogmático que depende em grande parte de sua própria grandiloquência e gravidade para funcionar como argumento. A professora maluquinha ameaça a ordem imposta pela escola ao permitir que se ria e que se possa sentir-se alegre durante suas aulas.

Neste ponto, é preciso dizer que trabalhamos com o riso neste artigo a partir do ponto de vista de Bakhtin (2013), que destaca o seu caráter ambivalente. Ao analisar o tema, o filósofo russo chama a atenção para o riso na Idade Média, fenômeno ligado às festividades da cultura popular e que possuía um caráter coletivo. Ali, o riso festivo funcionava como elemento de comunhão entre os participantes das comemorações populares, além disso, "Uma qualidade importante do riso na festa popular é que escarnece dos próprios burladores. O povo não se exclui do mundo em evolução. Também ele se sente incompleto; também ele renasce e se renova com a morte." (BAKHTIN, p. 10, 2013). Como se vê, o riso de que ele fala está distante do riso meramente irônico ou satírico em que o autor da brincadeira elege um alvo e o escarnece. Não se trata de rir de algo, mas de rir-se e de assim permitir-se renascer, daí o caráter ambivalente de que fala Bakhtin (2013), pois aquele que ri entende que é também um sujeito inacabado à mercê do erro, da incerteza e da falha. Todas essas características expulsam qualquer ideia de superioridade, de autoritarismo, afastando de si essas características que comumente povoam os discursos sobre a figura do professor. Por isso, justifica-se a atitude temerosa da diretora da escola ao tentar cercear o riso dentro do estabelecimento de ensino pelo qual é responsável.

Se a escola não admite que se ria em sala de aula, é para o espaço do recreio que a instituição expulsa o riso. Quando Larrosa (2015) nos alerta para o fato de que não se ri na escola, já está claro que não é sobre o riso recreativo que ele fala, mas então qual a diferença entre esses dois risos? Mais uma vez Bakhtin (2013) irá nos ajudar. Em seu texto, o filósofo fala de um outro riso, esse já desvinculado do seu caráter popular e ambivalente, o riso controlado. Bakhtin (2015) nos diz que as instituições da cultura oficial, mais precisamente a lgreja, percebendo a potencialidade do riso, trataram de organizá-lo, ou seja, de estabelecer espaços em que se permitiria ao povo saciar sua vontade de rir. Sobre isso, ele afirma:

Essa liberdade do riso, como qualquer outra liberdade, era evidentemente relativa; seu domínio se alargava ou diminuía alternadamente, mas não foi jamais totalmente interdita. [...] essa liberdade, em estreita relação com as 
festas, estava de certa forma confinada aos limites do dia da festa. Ela se fundia com a atmosfera de júbilo, com a autorização para comer carne e toucinho, de retomar a atividade sexual. Essa liberação do riso e do corpo (grifos do autor) contrastava brutalmente com o jejum passado ou iminente. (BAKHTIN, p. 77, 2013)

O riso, portanto, regulamenta-se, e o período em que pode se manifestar livremente apenas serve para reiterar sua condição de exceção e reforçar a sua clandestinidade diante dos ambientes em que não pode atuar. Trazemos essa reflexão para a análise de um episódio em que os alunos da professora maluquinha, sob o olhar assustado de três outras professoras do colégio, caminham na direção contrária a de uma placa em que se lê "Recreio". O texto diz: "As velhas professoras não entendiam nada. 'Os alunos dela acham melhor ficar na sala de aula do que brincar no recreio.' E repetiam: 'Esta menina é muito maluquinha'. ( ZIRALDO, p.38, 1995). No trecho em questão fica explícito o fato de que mais uma regra da escola fora quebrada. O que afinal é o recreio senão um espaço delimitado de tempo e de local em que as crianças podem rir e brincar, atividades proibidas em sala de aula? A mesma situação esboçada por Bakhtin (2013) se aplica nesse caso. A escola oferece essa oportunidade de recreação a fim de que as crianças possam ali fazer o que durante as aulas não é permitido. $O$ recreio é o local do riso regulamentado. $O$ mesmo autor russo já citara o exemplo ao escrever que "Durante as recreações, os jovens repousavam do sistema das concepções oficiais, da sabedoria e do regulamento escolares [...] libertavam-se, antes de mais nada, dos pesados entraves da piedade e da seriedade [...]." (BAKHTIN, p.72, 2013).

O recreio, portanto, serve como espaço não oficial em que a permissão do riso apenas confirma a sala de aula como o espaço oficial em que não há lugar para risadas. Diante desse sistema estabelecido, não é estranho que fuja à compreensão das professoras o fato de que as crianças estejam negligenciando 0 seu direito de poder rir e brincar durante alguns escassos minutos.

\section{OS RITUAIS ESCOLARES}

Nos exemplos trazidos até aqui é possível perceber o riso como característica da prática da professora maluquinha, também é flagrante a irritação que isso provoca na diretora da escola em que ela leciona. Esse riso, contudo, só é capaz de incomodar a chefe da instituição educacional, a ponto de, a certa altura do 
livro, fazê-la abrir a porta da sala de aula e gritar "Vamos parar com essa felicidade aí!" (ZIRALDO, p.75, 1995), porque a escola ainda se constitui como um espaço sagrado, onde as figuras do professor, do diretor e do saber são alçadas a uma esfera que as separa do mundo comum.

A tese defendida por Lipovestky (2005) de que vivemos em uma sociedade humorística, em que a noção de seriedade cedeu lugar a um culto do humor não se aplica à escola. $O$ autor afirma que:

Cada vez mais a publicidade, as emissões de animação, os slogans das manifestações, a moda adotam um estilo humorístico. [...] só a sociedade pós-moderna pode dizer-se humorística, só ela se institui globalmente sob a égide de um processo tendente a dissolver a oposição, até então estrita, do sério e do não-sério; na esteira das outras grandes divisões, a do cômico e do cerimonial esbate-se em benefício de um clima largamente humorístico. (LIPOVETSKY, p. 128, 2005)

Tendo em vista o campo da educação, embora muitos discursos institucionais possam dizer o contrário, não é possível afirmar que a escola faça parte dessa sociedade que rompeu com a oposição entre o sério e o não-sério como aponta o filósofo francês. Conforme já dissera Larrosa (2015), o riso nas instituições educacionais parece estar proibido, e justamente por isso é que ele mantém sua potência profanatória, pois só é possível profanar por meio do riso aquilo que ainda possui algum resquício de sacralidade (AGAMBEM, 2007).

Sobre o caráter restituidor da profanação, Agambem (2007, p.58) nos explica que:

"[...] se consagrar (sacrare) era o termo que designava a saída das coisas da esfera do direito humano, profanar, por sua vez, significava restituí-las ao livre uso dos homens. "Profano" - podia escrever o grande jurista Trebácio - "em sentido próprio denomina-se àquilo que, de sagrado ou religioso que era, é devolvido ao uso e à propriedade dos homens."

Desse modo, o distanciamento que presenciamos na sala de aula entre professor e aluno é uma prova da separação que confere ao mestre o caráter sacerdotal de que Larrosa nos fala. Separação que pode ser projetada em regulamentos e normas, mas que funciona também com base em uma espécie de aura de estabilidade e controle que recobre a instituição escolar.

A escola em que a personagem de Ziraldo leciona possui um caráter explicitamente ligado à religião, sendo o professor de catecismo um dos mais respeitados pelo corpo docente e pela comunidade. Ele é o responsável por proibir 
os alunos do grupo escolar de lerem histórias em quadrinhos, "Segundo o padreco, gibi era pecado!" (ZIRALDO, 1995, p.46) nos diz o narrador. Nesse ponto, é importante destacar novamente o caráter racional e disciplinar da escola e a função do currículo como documento que determina o que deve e o que não deve ser considerado como tema para a discussão em sala de aula.

Ao discutir a política e o currículo escolar, Silva (2000, p.11) nos diz que a política curricular "[...] tem efeitos na sala de aula. Ela define os papéis de professores e de alunos e suas relações [...] Ela determina o que passa por conhecimento válido e por formas válidas de verificar sua aquisição". Diante da proibição, a professora maluquinha mais uma vez transgride as regras escolares, incentivando seus alunos a trazerem suas revistinhas e gibis para a sala de aula e os utiliza como material didático, como o narrador descreve: "[...] a gente ficava lendo nossas revistinhas, nossos tico-ticos e gibis - já tinha menino lendo até Tarzan ou $O$ Espírito - além de outras revistas que ela mesma trazia de casa pra nos emprestar". (ZIRALDO, 1995, p.44). O padreco, contrariado pelas práticas da professora maluquinha, queixa-se com o seu superior, o Padre Velho:

Ele não dava sossego pra nossa professorinha. Vivia dizendo que ela era muito liberal, uma anarquista muito da maluquinha. E contava tudo para o Padre Velho, que, ao contrário dele, tinha a maior paciência com a sua maluquinha querida. (ZIRALDO, 1995, p.47)

Uma interessante característica que nos revela o trecho acima é a complacência que o Padre Velho demonstra ter com a professora. Erasmo de Roterdã (1982), em seu Elogio da loucura enfatiza a ideia de que a felicidade ligada à loucura é privilegio das crianças, mas que "[...] eu [a loucura] também mudo os anciãos à beira do túmulo, e, tanto quanto possível, os faço voltar à feliz idade da infância". (ROTERDÃ, 1982, p.24). Talvez por isso o Padre Velho, aspecto ressaltado pelo autor na escolha do sobrenome da personagem, identifique-se com a professora maluquinha e demonstre carinho por ela, ignorando as queixas de seu colega.

Como transgressão final, que resulta em sua dispensa, a professora maluquinha, ingenuamente, diz à diretora da escola que seus alunos não farão as provas finais. 
Antes que o ano terminasse, ela procurou a diretora e falou com segurança: 'Com as minhas crianças não vai ser preciso fazer provas. Todas têm condições de passar de ano'. A diretora achou que, agora, ela estava maluca de vez. (ZIRALDO, 1995, p. 93)

A insanidade da personagem de Ziraldo reside no fato de que ela não compreende a sacralidade do ritual das provas finais. Dentro da escola, a ideia de que uma turma inteira possa seguir para o próximo ano sem que nenhum deles tenha falhado em algum momento é inconcebível. A educação, como lembra Larrosa (2015, p.193) é "[...] obra de um pensamento calculador e de uma ação técnica, em que se trata de conseguir um produto real mediante a intervenção calculada num processo concebido com um espaço de possibilidades." Assim, já está previsto no itinerário escolar que as provas finais são inevitáveis, pois nelas reside, inclusive, um caráter de controle e de ameaça, por isso a sua não aplicação gera um temor tão grande na diretora da instituição. Dispensar os exames finais resulta na expulsão da personagem, afinal de contas, a escola não pode mais lidar com a ameaça em que a professora maluquinha se constituíra graças à sua prática profana de ensino.

\section{CONSIDERAÇÕES FINAIS}

A partir do estudo da obra e da sua personagem principal, o livro escrito por Ziraldo confirma as suspeitas levantadas com base na ilustração da obra e de seu título, e permite afirmar que a história retrata uma concepção profanadora de educação. A análise feita demonstrou que a professora maluquinha se torna capaz de profanar a escola em que leciona porque coloca em xeque três características que garantem à instituição escolar a posição de superioridade que a separa da esfera do que é humano.

A primeira delas a racionalidade, quando a professora maluquinha põe em risco a posição hierárquica e racional da escola e dela própria ao correr o risco de perder, participando com seus alunos dos jogos que propõe, e ao não responder a um questionamento dos estudantes, preferindo consultar um colega de outra área sobre aquele tema. A segunda, a do riso controlado, ao ameaçar a sacralidade da escola, permitindo que se ria e que se possa sentir-se alegre durante suas aulas. Agindo assim, a personagem faz com que os alunos desistam de sair da sala e 
frequentar o recreio, o que perturba a organização da escola, responsável por expulsar o riso para os espaços de exceção. Por fim, a professora maluquinha irá profanar os rituais sagrados da escola, permitindo que se leiam gibis e quadrinhos, gêneros proibidos na escola, e revelando à diretora que seus alunos não precisarão realizar as provas finais.

Se hoje parece fácil se assustar diante das situações presentes nesta obra de Ziraldo e de condenar as atitudes autoritárias da diretora da escola e de alguns colegas da professora maluquinha, a mesma facilidade não se encontra diante do desafio de dessacralizar a escola e restituí-la ao mundo cotidiano. Profanar a sala de aula significa oferecer a possibilidade de que se tenha um novo olhar sobre o processo de formação e de relação entre alunos e professores, mostrando a esses que estar disposto ao fracasso, ao não saber, é condição para que se possa se reinventar e modificar as identidades que lhe são conferidas.

A fim de propor uma educação profanadora, o uso do riso em sala de aula não deve ser confundido com a zombaria vazia de sentido em que tudo serve como motivo de sátira (DOZOL, 2003, p.20). O riso de que falamos é nas palavras de Larrosa (2015. p.170) "[...] um componente dialógico do pensamento sério [...]". Por isso ele não se contrapõe ao sério, mas o compõe na medida em que proporciona um espaço de auto-questionamento capaz de desnudar comportamentos e pressupostos que se autoproclamam racionais. A educação que aprisiona a formação humana e pressupõe a educação como uma mera técnica em que se colherão sempre os resultados esperados (LARROSA, 2015) se torna alvo de profanação justamente porque, segundo Agambem (2007), se constitui como ambiente sagrado, e toda existência de sacralidade pressupõe a profanação.

\section{REFERÊNCIAS}

AGAMBEN, Giorgio. Profanações. Tradução e apresentação de Selvino J. Assmann. São Paulo: Boitempo, 2007.

BAKHTIN, Mikhail. A cultura popular na Idade Média e no Renascimento. Tradução de Yara Frateschi Vieira. 8. ed. São Paulo: Hucitec Editora, 2013.

Questões de literatura e de estética: a teoria do romance. Tradução de Aurora Fornoni Bernardini et al. 2. ed. São Paulo: Hucitec, 1990. 
BAUMAN, Zygmunt. Identidade: entrevista a Benedetto Vecchi. Tradução de Carlos Alberto Medeiros. Rio de Janeiro: Jorge Zahar Ed., 2005.

CORACINI, Maria José R. Faria. As representações do saber científico na constituição da identidade do sujeito-professor e do discurso de sala de aula. In: CORACINI, Maria José R. Faria (org.). Identidade \& discurso: (des) construindo subjetividades. Campinas, SP: Editora da Unicamp; Chapecó: Argos Editora Universitária, 2003.

DOZOL, Marlene de Souza. Da figura do mestre. São Paulo: Editora da Universidade de São Paulo, 2003.

HALL, Stuart. A identidade cultural na pós-modernidade. Rio de Janeiro: Lamparina, 2014.

HERNÁNDEZ, Fernando. Transgressão e mudança na educação: os projetos de trabalho. Tradução de Jussara Haubert Rodrigues. Porto Alegre: ArtMed, 1998.

LARROSA, Jorge. Pedagogia profana: danças, piruetas e mascaradas. Tradução de Alfredo Veiga-Neto. 5. ed. Belo Horizonte: Autêntica Editora, 2015.

LIPOVETSKY, Gilles. A era do vazio. Barueri, SP: Manole, 2005.

ROTERDÃ, Erasmo de. Elogio da loucura. São Paulo: Novo Brasil Editora Brasileira Ltda. 1982.

SUBIRATS, Eduardo. Paisagens da solidão: ensaios sobre filosofia e cultura. São Paulo: Livraria Duas Cidades, 1986.

ZIRALDO. Uma professora muito maluquinha. São Paulo: Companhia Melhoramentos, 1995. 